\title{
Responsabilidad social en tres universidades argentinas Estrategias pedagógicas para su enseñanza
}

\author{
JUAN José GILLI* \\ Diana Rut SCHULMAN** \\ Noelia Anahí García*** \\ Argentina
}

\section{Resumen}

Este capítulo tiene como objetivo indagar la apropiación por parte de las estudiantes del concepto de Responsabilidad Social impartido en las materias específicas de la Licenciatura en Administración, dictadas en las universidades nacionales de Buenos Aires, La Plata y Luján.

\section{Introducción}

Se entiende a la universidad como un espacio que además de generar conocimiento y formar futuros profesionales, cumple una función

* Doctor en Ciencias Económicas y profesor consulto. Universidad de Buenos Aires. Contacto: jjoseg@hotmail.com

* Doctora en Ciencias Sociales (Flacso). Profesora asociada Universidad Nacional de Luján. Profesora adjunta Universidad de Buenos Aires. Contacto: dianarschulman@ gmail.com

***Licenciada en Administración y en Sistemas de Información de las Organizaciones. Profesora adjunta. Universidad de Buenos Aires. Contacto: noaga82@hotmail.com 
importante para la formación en valores. La educación superior debe contribuir al pensamiento crítico sobre los problemas éticos para el ejercicio de las distintas disciplinas; la tarea es, por cierto, compleja y plantea distintas cuestiones acerca de la posibilidad del desarrollo del juicio ético en los adultos y la forma de lograrlo por medio de la enseñanza.

En este sentido, se hace necesario estimular la comprensión de los problemas sociales, la construcción de un fundamento teórico y el desarrollo de actitudes socialmente responsables. Y para ello es preciso incluir la temática de la Responsabilidad Social (RS) en el currículo, disponer de estrategias pedagógicas apropiadas y contar con espacios integradores para el debate sobre las causas y las consecuencias de diferentes problemas sociales y el rol del futuro administrador frente a esa realidad.

Se considera que si bien el tema de la Ética y la Responsabilidad Social están instalados en la agenda de la discusión universitaria y estos temas han sido incorporados en los últimos años en el currículo de la educación superior, no están claras aún las estrategias pedagógicas adecuadas para su implementación.

Este capítulo se nutre del proyecto UBACyT "La enseñanza de la Responsabilidad Social en la formación de los futuros administradores" acreditado por la Secretaría de Ciencia y Técnica de la Universidad de Buenos Aires para el período 2013-2016, que tiene como objetivo indagar acerca del grado de apropiación por parte de los alumnos de los conceptos de Responsabilidad Social impartidos en las materias específicas de la formación de los licenciados en Administración, dictadas en las universidades nacionales de Buenos Aires, La Plata y Luján.

Se desarrollan aquí el marco conceptual base del proyecto en forma sintética y los resultados del trabajo de campo basado en una encuesta implementada a los alumnos que cursan las últimas asignaturas de la carrera mencionada en las tres universidades. Entre otras preguntas, se pone atención en las respuestas a la consulta sobre las estrategias pedagógicas que los estudiantes consideran apropiadas para el tratamiento de la temática de Responsabilidad Social, y las modalidades utilizadas por los docentes para el tratamiento de esta. 


\section{Marco conceptual}

En un trabajo anterior (Gilli, Schulman, y García, 2015) hemos desarrollado una perspectiva histórica de la Responsabilidad Social. Desde un punto de vista más amplio, la Responsabilidad Social representa una actitud consciente y madura de los problemas de la sociedad, al mismo tiempo que permite adoptar proactivamente hábitos que apuntan a minimizar los impactos negativos que genera toda actividad en el medioambiente y la sociedad. Así, ser socialmente responsable implica reconocer y aceptar las obligaciones que todos tenemos con nuestra comunidad, abarcando al mismo tiempo un comportamiento ético y un compromiso social. Es decir, que refleja un deber moral tanto individual como cuando se forma parte de un grupo social como una organización, empresa o institución gubernamental.

Drucker (1976), en su análisis sobre la administración y la calidad de vida, señala que si bien actuar con responsabilidad social exige mucho, pretende cosas justas, que los gerentes y la administración deberán tener en cuenta.

El comportamiento organizacional se asocia con el desempeño de la función del administrador, por tanto resulta imprescindible que el profesional en su etapa de formación tome conciencia del uso que realizará de los recursos y cuál será su responsabilidad ante la sociedad por la sustentabilidad de la organización que dirige o en la que se desenvuelve profesionalmente.

En consecuencia, se considera que los currículos de las carreras de Administración deben incluir, además de los temas técnicos, contenidos relacionados con la responsabilidad social. Asímismo, se entiende que el proceso de enseñanza-aprendizaje no solo opera sobre el contenido formal de los currículos y se vuelve necesario comprender que:

ningún estilo de convivencia es éticamente neutral (por lo que) la manera de "cohabitar juntos" y el uso diario de las infraestructuras e insumos del campus, designan un cierto ethos, una manera de ser y valorar ciertas actitudes más que otras, definir lo normal, lo habitual y lo que no lo es. (Valleys, s.f., p. 1) 
Existen numerosas estrategias utilizadas en universidades nacionales y extranjeras para el abordaje de la Rs. A modo de ejemplos, se mencionan las siguientes, desde las más "pasivas" a las más "participativas" (Torres, 2016):

En España, Antonio Argandoña de la Universidad Pontifica de Salamanca (1999) propone la enseñanza de la responsabilidad social por medio del "método del caso", mediante el cual se involucra al alumno en el proceso de aprendizaje y los coloca en una posición de constructor del conocimiento.

Otro método que se implementa hace años es el "aprendizaje basado en proyectos sociales”, el cual consiste en un conjunto de experiencias de aprendizaje que involucran a los estudiantes, profesores y personas de la comunidad en la solución de algún problema de orden social e incluye la "investigación-acción”.

En la Universidad del Zulia de Venezuela, se materializa el compromiso con la Rs mediante la implementación de un modelo académico de responsabilidad social centrado en la filosofía de "aprender haciendo" y "aprender prestando servicio". Martínez (2009) describe dichos programas que proponen un proceso de enseñanza-aprendizaje que plantea una diversificación de espacios de aprendizaje y de interacción de los actores con el entorno, propiciando oportunidades directas de atención y desarrollo comunitario.

Por otra parte, en la Universidad de Deusto proponen desarrollar un aprendizaje basado en competencias en tres áreas interrelacionadas (académica, profesional y cívico-social).

Los programas de liderazgo de servicio o de responsabilidad social buscan la formación de liderazgo en los estudiantes, de modo que se conviertan en profesionales con alto sentido de responsabilidad colectiva y sean capaces de encontrar un sentido a su profesión y a su vida como ciudadanos desde una perspectiva social.

En la Universidad de La Habana se utiliza la técnica de "juego de roles" para propiciar la reflexión de los estudiantes en torno al valor "responsabilidad social" durante el proceso de enseñanza-aprendizaje. Esta técnica participativa, a partir de la representación de un problema de la vida real del estudiante, estimula la reflexión en torno al mismo. 
En términos de currículo universitario, Samuel Natale y Sebastian Sora (2010) proponen un rediseño en las estructuras de los cursos. Proponen algunas materias imprescindibles para todos los estudiantes de negocios: Humanísticas, Liderazgo, Teoría de la Complejidad y Probabilidad Descriptiva. Incluyen trabajar con casos, videos, juego de roles y simulaciones que permitan analizar la traza de las decisiones hasta llegar a los fundamentos que las orientaron.

\section{Trabajo de campo}

Nuestra investigación tuvo como propósito general indagar acerca del grado de apropiación por parte de los futuros egresados de los conceptos de Responsabilidad Social impartidos en las materias específicas de su formación como administradores dictadas en las universidades nacionales de Buenos Aires, La Plata y Luján.

El diseño de la investigación es transversal, no experimental. Se trata de un estudio exploratorio-descriptivo en la medida en que lo que se busca es indagar sobre la incorporación de las cuestiones de responsabilidad social en el proceso de formación de los futuros profesionales en Administración. Las unidades de análisis son los alumnos próximos a graduarse en las carreras de Administración de las universidades nacionales de Buenos Aires, La Plata y Luján.

Tal como se adelantó en la introducción, nos ocuparemos particularmente de las estrategias pedagógicas para la enseñanza de los temas de responsabilidad social.

\section{Estrategias utilizadas para la enseñanza de la Responsabilidad Social}

El relevamiento se inició con una encuesta previa a alumnos de las últimas asignaturas de la carrera a fin de determinar los conceptos que se asocian más frecuentemente con la Responsabilidad Social. A partir de ese resultado se construyó un cuestionario con preguntas cerradas (escala de Likert, respuestas dicotómicas y multirespuesta) para 
encuestar a una muestra de alumnos de las últimas materias de las licenciaturas en Administración de las universidades nacionales de Buenos Aires, La Plata y Luján.

Las encuestas realizadas (por correo electrónico o en forma presencial) durante el segundo cuatrimestre del año 2014 y el primero de 2015, así como los respectivos universos, se muestran en el cuadro 1 :

Cuadro 1. Encuestas realizadas

\begin{tabular}{|l|c|c|}
\hline \multirow{2}{*}{\multicolumn{1}{|c|}{ Universidad }} & \multicolumn{2}{|c|}{ Por universidad } \\
\cline { 2 - 3 } & Total de alumnos & $\%$ Relevado \\
\hline Buenos Aires & 630 & $33 \%$ \\
\hline La Plata & 404 & $21 \%$ \\
\hline Luján & 219 & $29 \%$ \\
\hline
\end{tabular}

Total encuestado: $356-28 \%$ total.

Fuente: elaboración propia.

Pondremos nuestro foco de atención en uno de los objetivos específicos de la investigación: "identificar las estrategias de enseñanza puestas en juego por los docentes y su valoración por parte de los alumnos”.

Para esto se contrastaron las respuestas de los encuestados acerca de las estrategias utilizadas por los docentes con las que ellos consideran apropiadas para el tratamiento de los temas de Rs.

Se les consultó, en primer término, acerca de las estrategias pedagógicas utilizadas por los docentes para el tratamiento de los temas de Responsabilidad Social, pidiéndoles a los encuestados identificar cuáles son las que se utilizan con más frecuencia. Las respuestas se resumen en el cuadro 2 .

Del análisis de las respuestas surge claramente que en las tres universidades el enunciado de conceptos generales es la estrategia más usada y en menor medida la discusión de temas de actualidad.

Es interesante observar el porcentaje, aunque pequeño, de encuestados que no saben responder a la consulta (entre 3 y $9 \%$ en la UBA, y más aún en las otras dos universidades).

Observando la estrategia de análisis de casos, este se utiliza pocas veces o nunca en un porcentaje significativo (entre 61 y $82 \%$, según la universidad). 
Cuadro 2. Frecuencia con que los docentes utilizaron las estrategias pedagógicas para tratar los temas de RS

\begin{tabular}{|l|c|c|c|c|c|c|}
\hline & \multicolumn{2}{|c|}{ UBA } & \multicolumn{2}{c|}{ UNLu } & \multicolumn{2}{c|}{ UNLP } \\
\hline & $\begin{array}{c}\text { Nunca } \\
\text { / Pocas } \\
\text { veces }\end{array}$ & $\begin{array}{c}\text { Muchas } \\
\text { veces / } \\
\text { Siempre }\end{array}$ & $\begin{array}{c}\text { Nunca } \\
\text { / Pocas } \\
\text { veces }\end{array}$ & $\begin{array}{c}\text { Muchas } \\
\text { veces / } \\
\text { Siempre }\end{array}$ & $\begin{array}{c}\text { Nunca } \\
\text { / Pocas } \\
\text { veces }\end{array}$ & $\begin{array}{c}\text { Muchas } \\
\text { veces / } \\
\text { Siempre }\end{array}$ \\
\hline Análisis de casos & $61 \%$ & $34 \%$ & $64 \%$ & $30 \%$ & $82 \%$ & $11 \%$ \\
\hline $\begin{array}{l}\text { Discusión de te- } \\
\text { mas de actua- } \\
\text { lidad }\end{array}$ & $40 \%$ & $56 \%$ & $55 \%$ & $39 \%$ & $59 \%$ & $38 \%$ \\
\hline $\begin{array}{l}\text { Ejemplificación } \\
\text { de situaciones de } \\
\text { la práctica pro- } \\
\text { fesional }\end{array}$ & $48 \%$ & $46 \%$ & $54 \%$ & $38 \%$ & $61 \%$ & $36 \%$ \\
\hline $\begin{array}{l}\text { Enunciado de } \\
\text { conceptos gene- } \\
\text { rales }\end{array}$ & $24 \%$ & $71 \%$ & $31 \%$ & $54 \%$ & $27 \%$ & $65 \%$ \\
\hline $\begin{array}{l}\text { Mención al cum- } \\
\text { plimiento de } \\
\text { normas }\end{array}$ & $55 \%$ & $38 \%$ & $49 \%$ & $38 \%$ & $50 \%$ & $41 \%$ \\
\hline
\end{tabular}

Fuente: elaboración propia.

En Argentina no suele resultar sencillo acceder a información de las organizaciones locales, nacionales o internacionales para construir casos de estudio; por esto muchas veces se recurre a la utilización de ejemplos extranjeros, abundantes en manuales y textos de administración. Sin embargo, la utilización de análisis de casos resulta sumamente interesante porque no solo es un acercamiento a la realidad, sino que permite la discusión y el trabajo en equipo, aptitudes necesarias en el mundo profesional actual.

La discusión de temas de la realidad es utilizada nunca o pocas veces según más de la mitad de los encuestados de la UNLu y la UNLP (55 y $59 \%$, respectivamente), mientras que en la UBA el $56 \%$ indica que es utilizada muchas veces o siempre por los docentes. Desde nuestra perspectiva, los docentes podrían recurrir a múltiples ejemplos de la realidad cotidiana de nuestro país, para desarrollar cuestiones relacionadas con la temática de la Rs, destacando que actuar con responsabilidad social no solo implica el cuidado del ambiente como muchos estudiantes creen, sino una mirada hacia el interior de la organización 
(específicamente el personal) y las organizaciones con las que se interactúa (proveedores, clientes, entre otros actores).

Por su parte, la ejemplificación de situaciones de la práctica profesional refleja una situación similar a la anterior: en el caso de la UBA, existe similar proporción de respuestas que indican que los docentes la utilizan nunca o pocas veces $(48 \%)$ y muchas veces o siempre $(46 \%)$, mientras que en la UNLu y en la UNLP la mayoría indica que los docentes utilizan nunca o pocas veces esta estrategia pedagógica (54 y $61 \%$, respectivamente).

La inclusión de ejemplos de la vida profesional nos parece muy valiosa, teniendo en cuenta que muchos de los estudiantes tienen poca experiencia laboral y que al momento de obtener sus títulos habilitantes se enfrentan con situaciones impensadas para ellos.

Si bien aparece pocas veces, alrededor de un $50 \%$ de los docentes utiliza la mención al cumplimiento de normas para el tratamiento de temas relacionados con la Rs. Nuevamente, nos parece que esta lectura puede sumar a la simplificación del concepto de RS en los estudiantes.

\section{Estrategias apropiadas según los estudiantes encuestados}

Luego, respecto de las mismas estrategias pedagógicas, se solicitó a los estudiantes que indicaran cuáles les resultan más adecuadas para tratar los temas de responsabilidad social. Las respuestas unificadas pueden observarse en el cuadro 3.

Surgen importantes diferencias entre lo que los alumnos consideran las mejores estrategias pedagógicas para el tratamiento de los temas de nuestro interés y lo que los docentes utilizan en el aula.

El análisis de casos, les parece un modo muy o totalmente adecuado a alrededor del $90 \%$ de los encuestados en las tres universidades.

Si observamos la discusión de temas de actualidad aparece un porcentaje aún mayor, en torno del $95 \%$.

Por su parte, la ejemplificación de situaciones de la práctica profesional aparece como estrategia adecuada para los alumnos para abordar 
Cuadro 3. Estrategias que mejor les resultan a los alumnos encuestados para tratar los demas de RS

\begin{tabular}{|l|c|c|c|c|c|c|}
\hline & \multicolumn{2}{|c|}{ UBA } & \multicolumn{2}{c|}{ UNLu } & \multicolumn{2}{c|}{ UNLP } \\
\hline Nada / & $\begin{array}{c}\text { Mucho / } \\
\text { total- } \\
\text { mente }\end{array}$ & $\begin{array}{c}\text { Nada / } \\
\text { poco }\end{array}$ & $\begin{array}{c}\text { Mucho / } \\
\text { total- } \\
\text { mente }\end{array}$ & $\begin{array}{c}\text { Nada / } \\
\text { poco }\end{array}$ & $\begin{array}{c}\text { Mucho / } \\
\text { total- } \\
\text { mente }\end{array}$ \\
\hline Análisis de casos & $6 \%$ & $92 \%$ & $18 \%$ & $82 \%$ & $8 \%$ & $89 \%$ \\
\hline $\begin{array}{l}\text { Discusión de te- } \\
\text { mas de actua- } \\
\text { lidad }\end{array}$ & $3 \%$ & $95 \%$ & $5 \%$ & $95 \%$ & $3 \%$ & $96 \%$ \\
\hline $\begin{array}{l}\text { Ejemplificación } \\
\text { de situaciones de } \\
\text { práctica profe- } \\
\text { sional }\end{array}$ & $8 \%$ & $89 \%$ & $7 \%$ & $93 \%$ & $5 \%$ & $93 \%$ \\
\hline $\begin{array}{l}\text { Enunciado de } \\
\text { conceptos gene- } \\
\text { rales }\end{array}$ & $47 \%$ & $49 \%$ & $57 \%$ & $41 \%$ & $45 \%$ & $53 \%$ \\
\hline $\begin{array}{l}\text { Mención al cum- } \\
\text { plimiento de } \\
\text { normas }\end{array}$ & $43 \%$ & $50 \%$ & $33 \%$ & $60 \%$ & $47 \%$ & $50 \%$ \\
\hline
\end{tabular}

Fuente: elaboración propia.

la temática de Rs, donde entre un 89 y un $93 \%$ de los encuestados las refieren como mejores.

En cuanto al enunciado de conceptos generales, las cifras aparecen en torno de un $50 \%$ como muy o totalmente adecuadas y en relación con la mención al cumplimiento de normas, cerca la mitad de los estudiantes indican que la prefieren mucho o totalmente, mientras el resto señala que le resulta mejor. Por tanto, no es posible obtener conclusiones definitivas respecto de estas dos últimas estrategias en la preferencia de los estudiantes.

\section{Contrastación de resultados}

A continuación se comparan los resultados de las estrategias utilizadas por los docentes con las preferidas por los alumnos. 
Cuadro 4. Contrastación entre estrategias utilizadas por los docentes y las preferidas por los estudianes

\begin{tabular}{|l|c|c|c|c|c|c|}
\hline & \multicolumn{2}{|c|}{ UBA } & \multicolumn{2}{c|}{ UNLu } & \multicolumn{2}{c|}{ UNLP } \\
\hline tes & $\begin{array}{c}\text { Alum- } \\
\text { nos }\end{array}$ & $\begin{array}{c}\text { Docen- } \\
\text { tes }\end{array}$ & $\begin{array}{c}\text { Alum- } \\
\text { nos }\end{array}$ & $\begin{array}{c}\text { Docen- } \\
\text { tes }\end{array}$ & $\begin{array}{c}\text { Alum- } \\
\text { nos }\end{array}$ \\
\hline Análisis de casos & $34 \%$ & $92 \%$ & $30 \%$ & $82 \%$ & $11 \%$ & $89 \%$ \\
\hline $\begin{array}{l}\text { Discusión de te- } \\
\text { mas de actua- } \\
\text { lidad }\end{array}$ & $56 \%$ & $95 \%$ & $39 \%$ & $95 \%$ & $38 \%$ & $96 \%$ \\
\hline $\begin{array}{l}\text { Ejemplificación } \\
\text { de situaciones de } \\
\text { práctica profe- } \\
\text { sional }\end{array}$ & $46 \%$ & $89 \%$ & $38 \%$ & $93 \%$ & $36 \%$ & $93 \%$ \\
\hline $\begin{array}{l}\text { Enunciado de } \\
\text { conceptos gene- } \\
\text { rales }\end{array}$ & $71 \%$ & $49 \%$ & $54 \%$ & $41 \%$ & $65 \%$ & $53 \%$ \\
\hline $\begin{array}{l}\text { Mención al cum- } \\
\text { plimiento de } \\
\text { normas }\end{array}$ & $38 \%$ & $50 \%$ & $38 \%$ & $60 \%$ & $41 \%$ & $50 \%$ \\
\hline
\end{tabular}

Fuente: elaboración propia.

A simple vista, es posible observar las diferencias entre las herramientas utilizadas por los docentes y las que los estudiantes creen más adecuadas para el tratamiento de los temas de RS.

Si se considera que tanto el análisis de casos como la discusión de temas de actualidad y las ejemplificaciones de situaciones de la práctica profesional representan estrategias de intercambio y reflexión más participativas, se puede arriesgar que los estudiantes prefieren estas metodologías respecto del desarrollo de enunciados de conceptos generales y la mención al cumplimiento de normas que sugieren un tratamiento más tradicional y expositivo.

En general, aparece que las estrategias "preferidas" por los alumnos no son las que los docentes utilizaron con mayor frecuencia.

Cabe destacar que entre un 5 y un $15 \%$ de los encuestados no supieron responder acerca de las estrategias pedagógicas utilizadas por los docentes, mientras que sí supieron, al menos en mayor medida, indicar cuáles de ellas les resultan mejores. 


\section{Conclusiones}

Con la convicción de que es necesario incorporar en forma orgánica y generalizada los temas de ética y responsabilidad social en el currículo de las carreras universitarias de Administración, se ha trabajado en el equipo de investigación desde el año 2009.

En este capítulo y como parte de los resultados de una investigación mayor, se abordan específicamente las estrategias de enseñanza-aprendizaje utilizadas por los docentes para desarrollar la temática de Rs y las opiniones de los propios estudiantes acerca de cuáles de ellas consideran más adecuadas.

Se muestran a continuación las principales conclusiones del trabajo de campo.

- El análisis de casos, la discusión de temas de actualidad y la ejemplificación de situaciones de la práctica profesional parecen ser las estrategias preferidas por los alumnos ya que más del $80 \%$ de los encuestados que respondieron que les resultan mejor (mucho o totalmente). Sin embargo, al analizar con qué frecuencia los docentes las utilizaron surgen diferencias significativas: el análisis de casos se utiliza "nunca o pocas veces" entre el 61 y el $82 \%$ y la discusión de tema de actualidad entre el 55 y el $59 \%$.

- En cuanto al enunciado de conceptos generales y la mención al cumplimiento de normas, que parecen ser las estrategias pedagógicas más utilizadas por los docentes para tratar temas de responsabilidad social, cerca la mitad de los estudiantes indican que la prefieren "poco o nada".

- Cabe destacar que entre un 5 y un $15 \%$ de los encuestados no supieron responder acerca de las estrategias pedagógicas utilizadas por los docentes, mientras que sí pudieron, en mayor medida, indicar cuáles de ellas les resultan mejores.

Los futuros egresados de las tres universidades difieren con sus docentes en cuáles deberían ser las herramientas utilizadas para el tratamiento de la cuestión que nos ocupa. 
Responsabilidad Social de las Organizaciones (RSO)

De las estrategias que se presentaron anteriormente, no hay duda de que a mayor participación de los estudiantes mayor comprensión y compromiso con la temática se logrará.

Las formas de enseñanza de la Rs en la educación superior constituyen un tema vacante para investigar, innovar e implementar, evaluar y recrear. 


\section{Referencias}

Aguirre, R. de Pelekais, C. y Paz, A. (2012). Responsabilidad Social: compromiso u obligación universitaria. Telos. Revista de Estudios Interdisciplinarios en Ciencias Sociales, 14(1), 11-20.

Aldeanueva Fernández, I. y Jiménez Quintero, J. A. (2013). Experiencias internacionales en materia de responsabilidad social universitaria. Revista Visión de Futuro, 17(1).

Argandoña, A. (1999). La enseñanza de la ética por el método del caso. Salamanca: Universidad Pontificia de Salamanca.

Biktimirov, E.N. y Cyr, D. (2012). Using Inside Job to Teach Business Ethics. Journal of Business Ethics, 117, 209-219.

Caixeta, J., de Sousa, M. (2013).Responsabilidade social na educação superior: contribuições da psicologia escolar. Revista Semestral da Associação Brasileira de Psicologia Escolar e Educacional, sP, 17(1), 133-140.

Canelón, A. (2013). Responsabilidad Social Universitaria 2.0. Análisis de las páginas web de universidades de Ausjal. Revista Internacional de Relaciones Públicas, 5(III), 27-48.

Casilla, D. y Camacho, H. (2012). Evaluación de la Responsabilidad Social Universitaria. Facultad de Humanidades y Educación de Luz. Opción, Año 28, vol. 69, 452-465.

Dey, E. \& Associates (2008). "Should Colleges Focus More on Personal and Social Responsibility?”. Report. Center for the Study of Higher and Postsecondary Education. University of Michigan School of Education.

Drucker, P. (1976).La gerencia. Tareas, responsabilidades y prácticas. Buenos Aires: El Ateneo.

East, J., Donnelly, L. (2012). Taking Responsibility for Academic Integrity: A collaborative teaching and learning design. Journal of University Teaching \& Learning Practice, 9(3).

EU-USR (2013).Project title: Comparative research on the Social Responsibility of Universities in Europe and development of a Community reference framework. Erasmus Project.Website: http://www.eu-usr.eu/ University Politehnica of Bucharest.

Garde Sánchez, R., Rodríguez Bolívar, M. \& López-Hernández, A. M. (2013). Online Disclosure of University Social Responsibility: A Comparative 
Study of Public and Private us Universities. Environmental Education Research, 19(6), 709-746.

Gasca-Pliego, E.y Olvera-García, J. C. (2011). Construir ciudadanía desde las universidades, responsabilidad social universitaria y desafíos ante el siglo XxI. Convergencia (Revista de Ciencias Sociales), 18(56), 37-58.

Gilli, J.J., Schulman, D. y García, N. (2015). Temas de responsabilidad social en el currículo de tres universidades argentinas. En Gorrochategui, N., Martins de Olivera, M., Domínguez Granda, J. y Chero Valdivieso, H. Responsabilidad Social de las Organizaciones (RSO). Avances y propuestas en América Latina (pp.293-306). Recuperado de http://es.slideshare.net/capacitarse/rse-responsabilidad-social-de-las-organizaciones-sirso

Guillén, L. (2012). La responsabilidad social universitaria: un estudio de caso aplicado a la Universidad Autónoma del Caribe en Barranquilla, Colombia. Memorias VIII Congreso Internacional de Educación Superior Universidad 2012. La Habana, Cuba.

Hollister, R., Pollock, J., Gearan, M., Reid, J., Stroud, S. \& Babcock, E. (2012). The Talloires Network: A Global Coalition of Engaged Universities. Journal of Higher Education Outreach and Engagement, 16(4), p. 81.

Martínez, C., Rodríguez, J., Asprino, G. y Carvallo, B. (2009). Corresponsabilidad universitaria en la formación del capital social y responsabilidad social. Universidad del Zulia, Facultad de Ciencias Jurídicas y Políticas. Educa.

Pinheiro Barros, C., Freire, J. (2011). Responsabilidade social universitária na perspectiva do Sinaes: um estudo de caso no Curso de Medicina da Universidade Federal do Ceará - Campus de Sobral. Avaliação e Políticas Públicas emEducação, 19(73).

Rundle-Thiele, S. \& Wymer, W. (2010). Stand-Alone Ethics, Social Responsibility, and Sustainability Course Requirements: A Snapshot from Australia and New Zealand. Journal of Marketing Education, 32(1):5-12.

Natale, S.M. \& Sora, S.A. (2010). Exceeding Our Grasp. Curricular Change and the Challenge to the Assumptive World. Journal of Business Ethics, $92,79-85$.

Sánchez Arza, C. (2011) El rol de las universidades en el contexto de la responsabilidad social. XI Coloquio internacional sobre gestión universitaria en América del Sur. Florianópolis, 7-9 de diciembre de 2011.

Torres, F. (2016). Uso de estrategias pedagógicas efectivas en la enseñanza de la responsabilidad social de futuros administradores en la FCE-UBA. 
Trabajo final no publicado del Seminario Taller de Integración de la Especialización en Docencia Universitaria de la FCE-UBA.

Unesco (9 de octubre de 1998). Declaración Mundial sobre la Educación Superior en el siglo xxi: Visión y Acción y Marco de Acción Prioritaria para el Cambio y el Desarrollo de la Educación Superior, artículo 2. Recuperado dehttp://www.unesco.org/education/educprog/wche/declaration_spa.htm

Unesco, Conferencia Mundial sobre la Educación Superior: La nueva dinámica de la educación superior y la investigación para el cambio social y el desarrollo - París, Comunicado 5-8 de julio de 2009. Recuperado dehttp://unesdoc.unesco.org/images/0018/001832/183277s.pdf.

Vallaeys, F. (s.f.). El ethos oculto de la universidad. Recuperado dehttp://www. centroetica.uct.cl/documentos/archivos/PDF/H3\%2001.pdf 
